\title{
Effects of 2-(3,4-Dimethoxyphenyl)ethylamine Derivative (Ecabapide, DQ-2511) and Its Metabolites on Water-Immersion Restraint Stress-Induced Gastric Ulcers in Rats
}

\author{
Toru HosoKami, ${ }^{*}$ Yoshiaki TABUChI, and Kazuhisa Furuhama \\ Exploratory Research Laboratories III, Daiichi Pharmaceutical Co., Ltd., \\ 16-13, Kita-kasai 1-chome, Edogawa-ku, Tokyo 134, Japan
}

(Received September 20, 1994)

Ecabapide (DQ-2511) has been demonstrated to be effective in preventing water-immersion restraint stress ulceration of rats. In the present study, we aimed to define the active molecular features of ecabapide. Seven of 9 degraded materials identified as ecabapide metabolites were synthesized and their antiulcer activities were compared with that of the parent compound. Ecabapide was potent to prevent gastric ulcer formation at the doses of $30-300 \mathrm{mg} / \mathrm{kg}$ i.p. Three metabolites (V, VIII and IX) were also active to inhibit ulceration induced by the stress. The antiulcer activity of IX was similar to that of ecabapide, whereas $\mathrm{V}$ and VIII had less activities. After the oral administration of ecabapide, the plasma levels of IX reached to less than $15 \%$ of that of ecabapide and also IX was largely excreted into the feces. Therefore, the potential implication of the metabolite (IX) as the active component in the antiulcer effect of ecabapide could be excluded. Furthermore, it is also unlikely that the high polar metabolites (IV and VII) are implicated in significant contribution for antiulcer action. In conclusion, we have shown that ecabapide prevents waterimmersion restraint stress-induced gastric ulcers, and that this activity is probably mediated by the action of the parent compound.

Key words_-ecabapide (DQ-2511); metabolite; aminobenzamide; phenethylamine; stress ulcer

フェネチルアミンのアシル誘導体 ecabapide (3-[[[2-(3,4-dimethoxyphenyl)ethyl]carbamoyl]methyl]amino- $N$-methylbenzamide; Fig. 1) は，ラット水浸拘束ストレス潰瘍に対して強い抑制

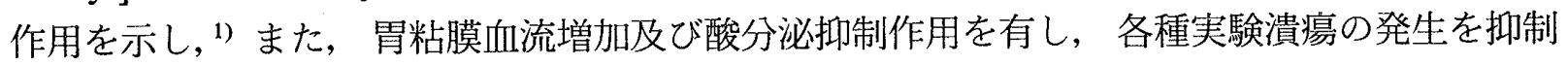
するのみならず治癒促進作用を有することも報告されている. ${ }^{2)}$ 幅広い抗潰瘍スペクトルを有 する ecabapide のラットでの代謝研究から，経口投与後の尿中及び粪中には ecabapide の他に カテコール系代謝物とフェネチルアミン系代謝物及び 7 種のアミノベンズアミド系代謝物が排 
泄されることが明らかにされている. ${ }^{3)}$

本研究では, ecabapide の主要代謝物 7 種を 合成し，これらの化合物の抗潰瘍作用を母化合 物の活性と比較することにより, ecabapide の 抗潰瘍活性がその代謝物に起因するか否かを調<smiles>CNC(=O)c1cccc(NCC(=O)NCCc2ccc(OC)c(OC)c2)c1</smiles>

Fig. 1. Chemical Structure of Ecabapide (DQ2511) ベることを目的に次のような実験を行った。

\section{实験材料及び方法}

1. 使用動物実験には, Donryu 系雄性ラット（10 週齢, 体重 290-340 g）を使用した (日本チャールス・リバー社)。動物は，糞食を避けるため金属網を敷いたケージを用い，温度 $23 \pm 2^{\circ} \mathrm{C}$, 湿度 $55 \pm 15 \%$ の環境下で飼育し, 市販の固形飼料（F-2, 船橋農場）及び上水道水を 自由に摂取させた。

2. 使用薬物 当社研究所にて合成した薬物を用い，すべて $0.5 \%$ carboxymethylcellulose sodium (CMC) 水溶液に懸濁し， $5 \mathrm{ml} / \mathrm{kg}$ の割合で投与した。

Ecabapide (3-[[[2-(3,4-dimethoxyphenyl)ethyl]carbamoyl] methyl]amino- $N$-methylbenzamide $)^{1)}$ 及び対照薬 cimetidine ${ }^{4}$ は文献記載の方法に従って合成した。文献に合成法が記載されていな W 3-acetamido- $N$-methylbenzamide (I), 3-acetamido- $N$-hydroxymethylbenzamide (III), 3-acetamidobenzamide (V), 5-acetamido-2-hydroxybenzamide (VI), $N$-[2-(3,4-dimethoxyphenyl)ethyl]oxamic acid (VIII), 3-[[[2-(3,4-dihydroxyphenyl)ethyl]carbamoyl]methyl] amino- $N$-methylbenzamide (IX) 及び文献記載化合物ではあるが異なった方法を用いた 5-acetamido-2-hydroxy- $N$ methylbenzamide (II) ${ }^{5}$ の合成法を示す。

3-Acetamido- $N$-methylbenzamide (I)-D-Amino- $N$-methylbenzamide ${ }^{6)}$ を乾燥ピリジンに溶解 し, 水冷撹拌下無水酢酸を加え，室温で 20 時間擋拌する，反応混合物を水水中に注ぎ，濃縮乾 固後エタノールーエーテルより再結晶し無色結晶 (I), mp 174-175 ${ }^{\circ} \mathrm{C}$ ，を得る.

5-Acetamido-2-hydroxy- $N$-methylbenzamide (II) — 5-Amino-2-hydroxybenzoic acid 塩化チ オニルーメタノール混合液に加え，室温下 2 日間懸濁擋拌して methyl 5-amino-2-hydroxybenzo-

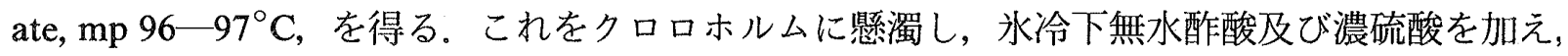
室温下 20 時間擋拌して methyl 5-acetamido-2-acetoxybenzoate, mp 134-135 ${ }^{\circ} \mathrm{C}$ ，とする。これを $40 \%$ チルアミン水溶液に懸濁し, 室温下 20 時間擋挥して, 無色結晶 (II), mp $197-199^{\circ} \mathrm{C}$ （含水エタノールより再結晶），を得る.

3-Acetamido- $N$-hydroxymethylbenzamide (III)—-3-Acetamidobenzamide, 37\% ホルムアルデ ヒド水溶液及び炭酸カリウムをテトラヒドロフラン $(\mathrm{THF})$ に加え, 5 時間加熱還流, 冷却後有 機層を濃縮し，ダイヤイオンHP20を用いたカラムクロマトグラフィーにて精製（展開溶媒： $3 \% \mathrm{THF}$ 含有水溶液). 流出液を減圧下 $40^{\circ} \mathrm{C}$ にて濃縮し無色結晶 (III), $\mathrm{mp} 136-140^{\circ} \mathrm{C}$, を得 る.

3-Acetamidobenzamide (V)—-Aminobenzamide 乾燥ピリジンに溶解し，無水酢酸を加 え室温下撹抖. 一夜放置後, 反応混合物を水水に加え，無色結晶 $(\mathrm{V}), \mathrm{mp} 219-220^{\circ} \mathrm{C}$ (メ夕 ノールより再結晶)，を得る.

5-Acetamido-2-hydroxybenzamide (VI)-Methyl 5-acetamido-2-acetoxybenzoate $28 \%$ ア ンモニア水に懸濁し，室温下 2 日間擋拌後濃縮乾固して，無色結晶 (VI), $\mathrm{mp} 211-212^{\circ} \mathrm{C}(I$ タノールより再結晶), を得る。 
$N$-[2-(3,4-Dimethoxyphenyl)ethyl]oxamic Acid (VIII)—-2-(3,4-Dimethoxyphenyl)ethylamine 及びトリエチルアミンをジクロルメタンに溶解. 氷冷下 ethyl chloroglyoxylate を加えて擋拌し ethyl $N$-[2-(3,4-dimethoxyphenyl)ethyl]oxamate, $\mathrm{mp}$ 66-69 $\mathrm{C}$ （エタノールーエーテルより再結 晶)，を得る。これを $1 \mathrm{~N}$ 水酸化ナトリウム溶液一エタノール混液に加え, 室温で 2 時間擋拌.こ の溶液を塩酸にて酸性とし, 酢酸エチルエステルにて抽出, 濃縮して無色結晶 (VIII), mp $129-131^{\circ} \mathrm{C}$ (クロロホルムートルエンより再結晶), を得る.

3 -[ [[2-(3,4-Dihydroxyphenyl) ethyl] carbamoyl] methyl] amino- $N$-methylbenzamide (IX)Ecabapide をジクロルメタンに溶解し, ドライアイスーアセトンで泠却下三臭化ホウ素を滴下, 擋汼. 反応混合物を水水に注ぎ，水層より淡黄色結晶 (IX), $\mathrm{mp} 222-224^{\circ} \mathrm{C}$ (メタノールより 再結晶), を得る.

3. 実験方法 1) 水浸拘束ストレス潰瘍の惹起一一水浸拘束ストレス潰瘍は高木らの方 法7に準拠して作出した。すなわち, 非絶食ラットを水浸拘束ストレスケージに入れ, 動物の剣 状突起レベルまで水に没し $21^{\circ} \mathrm{C}$ で 7 時間水浸拘束負荷を施した. エーテル麻酔下にラット腹 部を正中線に沿って切開し, 胃を摘出後, 胃管腔側に $2 \%$ ホルマリン緩衝液 $10 \mathrm{ml}$ を注入し, さ らに同ホルマリン緩衝液中で室温，20 分間軽度に固定した。その後，固定した胃を大弯に沿っ て切開し, 潰瘍係数を算出した. すなわち, 個々の動物の出血壊死病変部の長軸の長さをノギ スで計測し，合計したものを潰瘍係数とした。被検薬はストレス負荷 30 分前に腹腔内投与し た。ただし，対照薬 cimetidine は経口投与した。

2) 統計学的処理一一結果は平均土標準誤差で示した $(N=8)$. 各試験の群間の有意差検定 は, Dunnett の多重比較法により行い, 有意水準 5\%で判定した。 $\mathrm{ED}_{50}$ 值は用量反応曲線から 算出し, $\mu \mathrm{mol} / \mathrm{kg}$ で表した。

結 果

水浸拘束ストレス潰瘍モデルを用い, ecabapide 及びその代謝物 (I, II, III, V, VI, VIII, IX) を腹腔内投与し，それらの抗潰瘍作用を評価し た。水浸拘束ストレス負荷 $\left(21^{\circ} \mathrm{C}, 7\right.$ 時間) によ り対照群のラットでは全例に胃体部粘膜に線状 の出血性黑色胃粘膜壊死が形成された。対照群 の潰瘍係数は，実験群間で $28.0 \pm 4.0$ から 44.6 \pm 6.8 の範囲で変動がみられたが, 薬物効果の 評価には対照群に常時 cimetidine 投与群を設 け, その顕著な抗潰瘍効果（実験群間で 81一 98\%，平均 92\%）を確かめ, 被験薬の効果を代 謝物投与群の潰瘍係数とそれに対する対照群の 潰瘍係数から潰瘍抑制率として算出し, 比較し た。

Cimetidine $(200 \mathrm{mg} / \mathrm{kg})$ を経口投与, ecabapide 及びその 7 種の代謝物 $(300 \mathrm{mg} / \mathrm{kg})$ を腹腔 内投与した時の抑制作用を Fig. 2 に示す。対照 薬 cimetidine は再現性の高い顕著な抗潰瘍作用

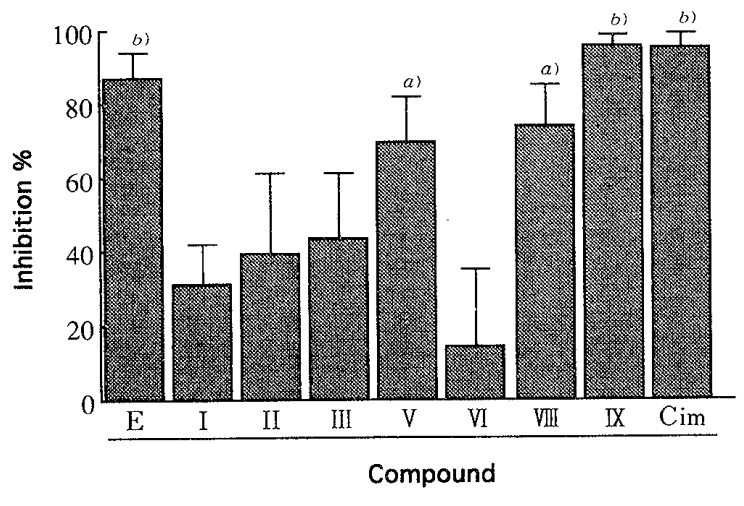

Fig. 2. Antiulcer Effects of Ecabapide, Its Metabolites and Cimetidine on Water-Immersion Restraint Stress-Induced Gastric Ulcers in Rats

Ecabapide (E) or its metabolites (300 $\mathrm{mg} / \mathrm{kg}$, i.p.) and cimetidine (Cim; 200 $\mathrm{mg} / \mathrm{kg}$, p.o.) were administered $30 \mathrm{~min}$ pior to the stress loading. All data indicate means \pm S.E.M. $(N=8)$.

a) $p<0.05, b) p<0.01$ vs. vehicle control group (Dunnett's multiple comparison). 
TABLE I. Antiulcer Effects of DQ-2511 and Its Metabolites on Water-Immersion Restraint Stress-Induced Gastric Ulcers in Rats

\begin{tabular}{|c|c|c|c|c|c|c|}
\hline \multirow{2}{*}{ Compound } & \multicolumn{5}{|c|}{ Dose $(\mathrm{mg} / \mathrm{kg})$} & \multirow{2}{*}{$\begin{array}{c}\mathrm{ED}_{50} \\
(\mu \mathrm{mol} / \mathrm{kg}\end{array}$} \\
\hline & 0 & 30 & & 100 & 300 & \\
\hline Ecabapide & $44.6 \pm 6.8$ & $25.7 \pm 5.1^{\circ}$ & $(42)$ & $12.0 \pm 3.3^{b)}$ & $5.8 \pm 3.2^{b)}(87)$ & 105 \\
\hline V & $28.0 \pm 4.0$ & $22.4 \pm 7.3$ & $(20)$ & $15.8 \pm 6.6$ & $8.6 \pm 3.4^{a)}(69)$ & 707 \\
\hline VIII & $32.5 \pm 5.4$ & $27.4 \pm 7.7$ & (16) & $11.6 \pm 5.2^{a)}(64)$ & $\left.8.7 \pm 3.8^{a}\right)$ & 367 \\
\hline IX & $32.9 \pm 4.0$ & $17.0 \pm 5.5^{b}$ & $(48)$ & $3.7 \pm 2.8^{b)}$ & $1.6 \pm 1.0^{b)}$ & 76 \\
\hline
\end{tabular}

Each compound was administered intraperitoneally $30 \mathrm{~min}$ prior to the stress loading. All data indicate means \pm S.E.M. $(N=8)$. a) $p<0.05, b) p<0.01$ vs. vehicle control group (0 dose) (Dunnett's multiple comparison). Figures in the parentheses indicate the percent inhibition.

(81一98\%) を示した。 Ecabapide の腹腔内投与は潰瘍発生を有意に抑制し，その抑制率は $87 \%$ であった。また，アミノベンズアミド系代謝物 (V) 毛潰瘍発生を有意に抑制し，その抑制率は 60\% 以上であったが，その他のアミノベンズアミド系代謝物 (I, II, III, VI) は有意な抑制作用 を示さず，抑制率はいずれも50\%未満であった。 Ecabapide の酸化的代謝物で，アミノベンズ アミドの 3 位アミノ基とメチレンとの結合が開裂して生じた代謝物 (VIII) は潰瘍発生を有意 に抑制し，その抑制率は70\%を上回るものであった。 また，ecabapideのメチル基が脱離して 生じたカテコール体 (IX) は ecabapide と同等の有意な抗潰瘍作用を示した.

投与量 $300 \mathrm{mg} / \mathrm{kg}$ で $50 \%$ 以上の抑制作用を示した ecabapide, V, VIII 及び IX について，30$300 \mathrm{mg} / \mathrm{kg}$ の範囲で水浸拘束ストレス潰瘍に対する抑制作用について用量反応関係を調べ, $\mathrm{ED}_{50}$ 值を算出し，活性比を比較した (Table I). Ecabapide の 30,100 及び $300 \mathrm{mg} / \mathrm{kg}$ の腹腔内投 与はストレス誘発潰瘍を用量に依存して有意に抑制し，それぞれの抑制率は $42 ， 73$ 及び $87 \%$ であり，その $\mathrm{ED}_{50}$ 值は $105 \mu \mathrm{mol} / \mathrm{kg}$ であった。 また，V は $300 \mathrm{mg} / \mathrm{kg}$ 腹腔内投与時のみ潰瘍発 生を有意に抑制し (69\%)， $\mathrm{ED}_{50}$ 值は $707 \mu \mathrm{mol} / \mathrm{kg}$ であった。VIII の 100 及び $300 \mathrm{mg} / \mathrm{kg}$ の腹空 内投与は潰瘍発生を有意に抑制し，それぞれの抑制率は 64 及び $73 \%$ であり， $\mathrm{ED}_{50}$ 值は 367 $\mu \mathrm{mol} / \mathrm{kg}$ であった．カテコール体 (IX) の 30,100 及び $300 \mathrm{mg} / \mathrm{kg}$ の腹腔内投与は，用量に依存 して有意に潰瘍を抑制し，それぞれの抑制率は 48,89 及び $95 \%$ であり， $\mathrm{ED}_{50}$ 值は $76 \mu \mathrm{mol} / \mathrm{kg}$ であった。

\section{考察}

Fig. 3 に，現在までに同定されているラットでの ecabapide の代謝物と代謝経路を示す.

ラットでの薬物代謝の研究は ecabapide の 2 種の ${ }^{14} \mathrm{C}$ 標識体を用い，HPLC 法による代謝物 の同定を中心に行われてきた。すすねお，ベンズアミドのベンゼン環炭素の ${ }^{14} \mathrm{C}$ 標識体を用い た検討によりアミノベンズアミド系代謝物として，I, II, III, 5-acetamido-2-hydroxy-N-hydroxymethylbenzamide (IV), V, VI 及び VII（II のグルクロン酸抱合体）が尿中より同定されている. この結果から，ecabapideのアミノベンズアミド部分の 3 位アミノ基とメチレンとの結合が開 裂し，生成したアミノベンズアミドは，N-アセチル化，ベンゼン環の水酸化とグルクロン酸抱 合化， $N$-メチル基の水酸化及び $N$-脱メチル化等の代謝を受けて尿中へ排泄されることが明ら かとなった，また，フェニルェチルアミノ基の 1 位炭素の ${ }^{14} \mathrm{C}$ 標識体を用いた検討より，VIII が尿中より検出されている。この結果も ecabapide は主にアミノベンズアミドの 3 位アミノ基 とメチレンとの結合が開裂し，代謝を受けることを示唆している，さらに，カテコール体 (IX) 


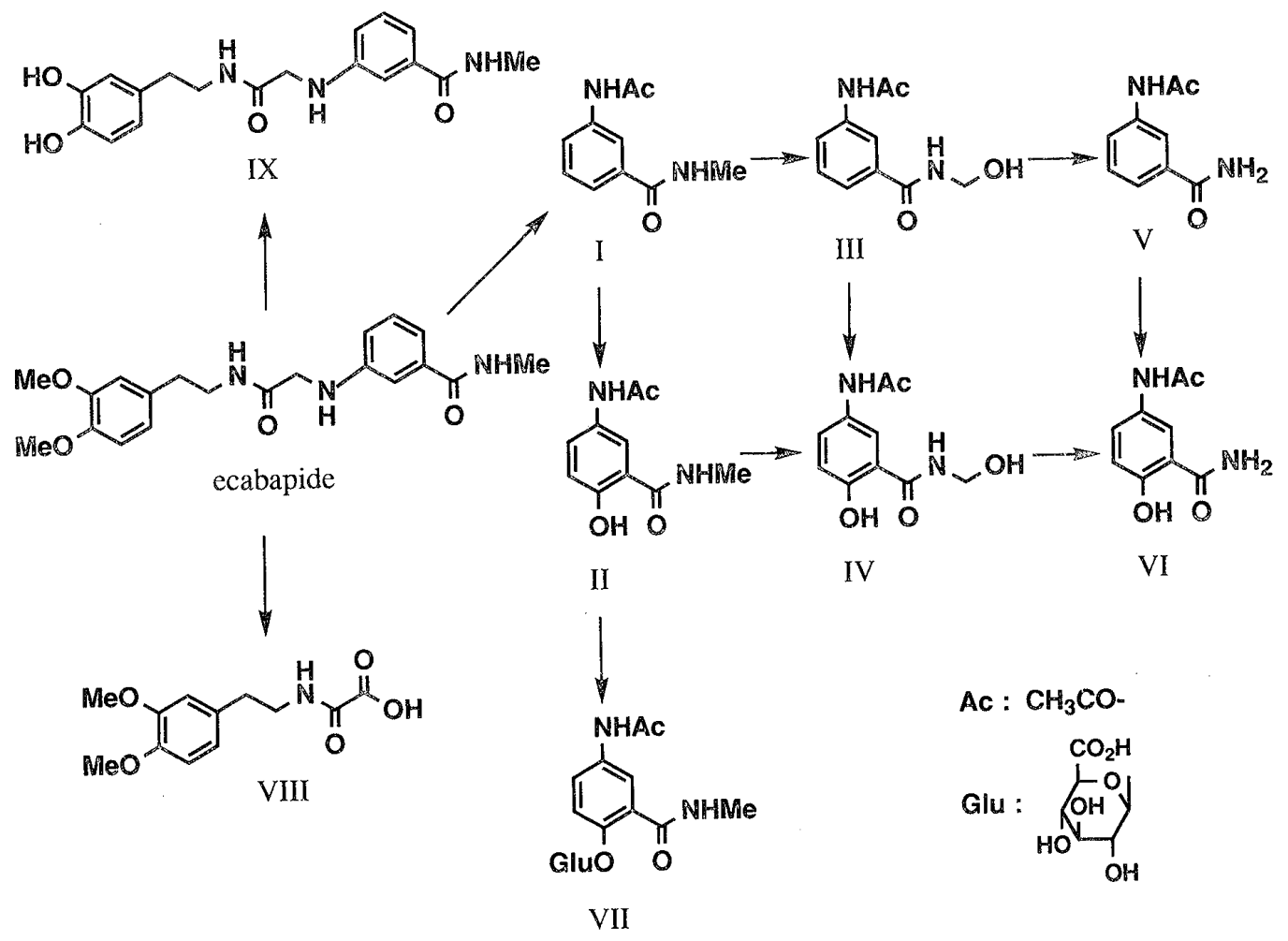

Fig. 3. Tentative Metabolic Pathways of Ecabapide in Rats

がラット粪中より単離同定され, ecabapide が $O$-脱メチル化される代謝経路の存在する可能性 屯示されている。

今回, ecabapide の抗潰瘍作用が ecabapide 自体の作用によるのか，代謝物の作用によるもの かを明らかにすることを目的として，ecabapide 及びラット尿または䔬中より見い出されてい る代謝物の活性を比較検討した。 その結果，検討した 8 化合物の中で $300 \mathrm{mg} / \mathrm{kg}$ 腹腔内投与で 有意な抗潰瘍作用を示したのは ecabapide 及び V, VIII, IX の 4 化合物であった。 Ecabapide は 30,100 及び $300 \mathrm{mg} / \mathrm{kg}$ の腹腔内投与で水浸拘束ストレス潰瘍を用量依存的かつ有意に抑制し, それぞれの抑制率は 42,73 及び $87 \%$ で，その $\mathrm{ED}_{50}$ 值は $105 \mu \mathrm{mol} / \mathrm{kg}$ であった．Vの抗潰瘍作 用は，抑制率 69\% (300 mg/kg 腹空内投与)， $\mathrm{ED}_{50}$ 值 $707 \mu \mathrm{mol} / \mathrm{kg}$ であり， ecabapide に比べかな り弱かった。 また，ecabapide $(100 \mathrm{mg} / \mathrm{kg})$ を経口投与し，血漿中濃度が最高值に達する 2 時間 後では未変化体が $29 \%$ と最も高い存在率を示す一方，Vの血漿中存在率は $4.9 \%$ であった こ とから, ecabapide の抗潰瘍作用発現に対するV の寄与は極めて小さいものと考えられた。 VIII は $100 \mathrm{mg} / \mathrm{kg}$ 及び $300 \mathrm{mg} / \mathrm{kg}$ 腹腔内投与時に抑制作用を示したが，その $\mathrm{ED}_{50}$ 值は ecabapide の 3 倍以上であった。 また，VIII は尿中に見い出された代謝物であり，その血漿中存在率は ecabapide と比較すると低く作用発現への寄与は小さいと考えられた. IX は $30 \mathrm{mg} / \mathrm{kg}$ 腹腔内投与 から用量依存的に抗潰瘍作用を示し，この作用は ecabapide とほぼ同等もしくはそれ以上の強 い $\left(\mathrm{ED}_{50}\right.$ 值: $\left.76 \mu \mathrm{mol} / \mathrm{kg}\right)$ あのであった。しかし，IXは䔬中には多く存在するあのの, ecabapide 経口投与 2 時間後の IX の血漿中存在率は $4.2 \%$ と低く，未変化体 $(29 \%)$ に比べ血漿中には少 量認められたのみであった。これらの結果を考え合わせると，IX の潰瘍発生抑制作用への寄与 は，V 及び VIII と同樣にわずかであると考えられた。 また，その他の代謝物 (I, II, III, VI) の $300 \mathrm{mg} / \mathrm{kg}$ 腹空内投与は有意な抑制作用を示さず，これらの代謝物屯抑制作用発現の本体とは 
なり得ないと考えられた。

I, II, III の抗潰瘍作用は $300 \mathrm{mg} / \mathrm{kg}$ の用量であ弱く有意な作用が認められなかったことから， IV 及び VII が活性本体とは考えにくいため，これらの水浸拘束ストレス潰瘍抑制作用につい ては検討しなかった。

今回の検討結果からは，単離同定されているIからIXの代謝物のいずれかが活性本体とは 考え難く，未変化体 ecabapide が抗潰瘍作用に大きく奇与していることが示唆された.

\section{引用 文 献}

1) T. Hosokami, M. Kuretani, K. Higashi, M. Asano, K. Ohya, N. Takasugi, E. Mafune, T. Miki, Chem. Pharm. Bull., 40, 2712 (1992).

2) M. Asano, Y. Kurebayashi, Y. Ryoukawa, T. Hashizume, A. Akashi, Arzneim.-Forsch., 40, 276 (1990).

3) 藤巻ゆう子，小野健司，伯水英夫，薬物動態，5,546 (1990).

4) D. J. Graham, E. C. John, G. R. Charon, Ger. Patent 2344779 (1974) [Chem. Abstr., 80, $146168 j(1974)]$.

5) B. Grandnik, A. Pedrazzoli, G. Cipelletti, Br. Patent 1047028 (1966) [Chem. Abstr., 66, $37667 m$ (1967)].

6) M. R. Purnell, W. J. D. Wish, Biochem. J., 185, 775 (1980).

7) K. Takagi, S. Okabe, Jpn. J. Pharmacol., 18, 9 (1968). 